\title{
The Transactivating Function 2 (AF-2) of Estrogen Receptor (ER) $\alpha$ Is Indispensable for ER $\alpha$-Mediated Physiological Responses and AF-1 Activity
}

\author{
Yukitomo Arao, Katherine J. Hamilton, Kenneth S. Korach* \\ Receptor Biology Section, Laboratory of Reproductive and Developmental Toxicology, \\ National Institute of Environmental Health Sciences/NIH, Research Triangle Park, North Carolina, USA \\ Email: *korach@niehs.nih.gov
}

Received May 11, 2013; revised June 11, 2013; accepted July 11, 2013

Copyright (C) 2013 Yukitomo Arao et al. This is an open access article distributed under the Creative Commons Attribution License, which permits unrestricted use, distribution, and reproduction in any medium, provided the original work is properly cited.

\begin{abstract}
Estrogen has various physiological functions and the estrogen receptor (ER) is a key regulator of those functions. ER $\alpha$ is a ligand-dependent transcription factor and that activity is mediated by the transactivating function-1 (AF-1) in the $\mathrm{N}$-terminal domain and transactivating function-2 (AF-2) in the C-terminal ligand-binding domain. The functions of $\mathrm{ER} \alpha \mathrm{AF}-1$ and AF-2 have been characterized by various in vitro experiments, however, there is still less information about the in vivo physiological functions of ER $\alpha$ AF-1 and AF-2. Recently, we established a genetically mutated ER $\alpha$ AF-2 knock-in mouse (AF2ERKI) that possessed L543A, L544A mutated-ER $\alpha$. This AF-2 core mutation disrupted AF-2 function and resulted in ER $\alpha$ null phenotypes. This mouse model revealed that proper AF-2 core structure and function were indispensable for ER $\alpha$-mediated physiological responses and AF-1 functionality. AF2ER mutation reverses the ER $\alpha$ antagonists to agonists and that activity is mediated by AF-1 solely. The pure antagonist, ICI182780/fulvestrant, activated several estrogen-mediated physiological responses in the AF2ERKI mouse. The AF2ERKI mouse model will be useful to discern estrogen physiological functions which involve AF-1.
\end{abstract}

Keywords: Knock-In Mouse; SERMs; Antagonist Reversal

\section{Introduction}

\subsection{Transcriptional Activation Domains in Estrogen Receptor}

Estrogen receptor (ER) is a member of the nuclear receptor superfamily which share highly conserved domain structures, including the DNA binding domain (DBD) and ligand binding domain (LBD) [1,2]. The DBD is localized in the middle of the protein and the carboxylterminal (C-terminal) end of the protein possesses the LBD. In contrast, the structure of the amino-terminal (Nterminal) end is varied between the nuclear receptors [3]. The transcriptional activation function (AF) domains of $\mathrm{ER} \alpha$ are distributed in the N-terminal (known as AF-1) and C-terminal (known as AF-2) of the ER protein. AF-2 is localized in the LBD on helix 12, an element in the LBD that is defined as the core of the AF-2 region [4,5]. The configuration of helix 12 is changed by the ligand binding to the LBD which induces a transcriptionally

\footnotetext{
${ }^{*}$ Corresponding author.
}

active or inactive form of the receptor. When agonists (transcription activating chemicals) bind to the LBD, helix 12 makes a co-activator binding surface and recruits transcriptional co-activators, such as SRC1/p160, SRC2/GRIP1and SRC3/AIB1 to the LBD [6]. On the other hand, when antagonists (transcription inactivating chemicals) bind to the LBD, helix 12 is relocated to prevent the co-activator binding and recruits transcriptional co-repressors to the LBD $[7,8]$. Thus the AF-2 is designated as a "ligand-dependent" transcription regulation domain. The N-terminal of ER $\alpha$ possesses the constitutively active transcriptional domain (AF-1), because of the fact that the deletion of the LBD from the ER $\alpha$ protein induces high basal activity $[9,10]$. This basal activity of $\mathrm{ER} \alpha \mathrm{AF}-1$ is dependent upon the gene promoter context and cell types [10]. Several phosphorylation sites have been identified in the N-terminal end of the ER $\alpha$ protein, such as serines 104/106 [11], serine 118 [12,13] and serine 168 [14] on human ER $\alpha$ and serine 122 on mouse $\mathrm{ER} \alpha$ (identical to serine 118 of human $\mathrm{ER} \alpha$; [15]). It has been reported that the phospho-status of the N- 
terminal modulates the transcription activity of ER $\alpha$ independently of estrogen ligand $[11,16,17]$. Thus, the AF-1 is designated as a "ligand-independent" transcription regulation domain.

\subsection{Estrogenic Compounds}

Various estrogenic-active compounds (agonists) have been identified using the binding assay with $\mathrm{ER} \alpha$ protein [18-20], or using the reporter assay with a full-length $\mathrm{ER} \alpha$ protein expressed yeast [21] or with $\mathrm{ER} \alpha$ positive mammalian cells [22]. These compounds include both man-made chemicals and the natural compounds (known as xenoestrogens) which have various chemical structures. Various estrogen receptor antagonists and selective estrogen receptor modulators (SERMs) have been developed in pharmaceutical research by analyzing derivatives of certain estrogenic compounds [23-25]. Tamoxifen (4-hydoxytamoxifen; 4OHT) is one of the most wellcharacterized SERMs. 4OHT displays both agonistic and antagonistic effects in a tissue specific manner, namely, $4 \mathrm{OHT}$ is an agonist in uterine tissue but works as an antagonist in the mammary gland [26]. A well- known pure antagonist, fulvestrant/ICI182780 (ICI) has been classified as a selective estrogen receptor down-regulator (SERD), which induces ER $\alpha$ protein degradation [27-29]. Thus, the binding affinity to $\mathrm{ER} \alpha$ is not simply correlated to the transcriptional activity of estrogenic chemicals. It has been reported that the partial agonist activity of $4 \mathrm{OHT}$ is only derived from $\mathrm{ER} \alpha \mathrm{AF}-1$ activity and that is a major cause of tissue selective action of 4OHT [10]. It is important to determine if estrogenic action of chemicals involves a preference of AF-1 in order to understand the tissue specific action of estrogenic responsiveness. However, to date there is little information about the AF1 dependency of estrogenic chemicals.

\section{AF-2 Inactivated ER $\alpha$ Mouse Model (AF2ERKI)}

\subsection{Generation of AF2ERKI Mouse Model}

The various physiological roles of $\mathrm{ER} \alpha$ have been previously demonstrated by the $\mathrm{ER} \alpha$ knock-out ( $\alpha \mathrm{ERKO}$ ) mouse model [30]. The $\alpha \mathrm{ERKO}$ does not express functional $\mathrm{ER} \alpha$ protein as a result of a genetic modification of the Esr1 allele [31,32]. Thus this model cannot discern the selective functionality of $\mathrm{ER} \alpha \mathrm{AF}-1$ or AF-2 in $\mathrm{ER} \alpha-$ mediated physiological responses in vivo. To assess the effect of loss of AF-2 function in vivo, we generated the AF-2 mutated knock-in (KI) mice (AF2ERKI) through the modification of the Esr1 allele [33,34]. AF2ERKI possesses the following mutations: the leucines 543 and 544 of mouse $\operatorname{ER} \alpha$ were mutated to alanines and a $6 \mathrm{x}$ His-tag was added to the C-terminal end of the ER $\alpha$ protein (Figure 1). Leucines 543 and 544 are components of helix 12 and the mutation of those residues causes disruption of E2-mediated transcription without the reduction of ligand binding activity [35].

\subsection{AF2ERKI Homozygote Female Reproduction}

Continuous breeding studies indicated that AF2ERKI homozygote females were infertile. The AF2ERKI female does not display signs of a normal estrous cycle and vaginal smears display a pattern of persistent diestrus. The serum LH level, which is an end point linked to reproductive cyclicity and responsiveness, was elevated in AF2ERKI 4-fold over the wild-type (WT) female. The serum E2 level of AF2ERKI was 2-fold higher than the WT female [33]. These hormone levels in the AF2ERKI female were similar to the $\alpha$ ERKO female. Such elevated LH levels suggest that the negative feedback of the hypothalamic-pituitary gonadal axis in the AF2ERKI female is disrupted as has been reported in the $\alpha \mathrm{ERKO}$ animals [30], consistent with the infertility. The uterine tissues of AF2ERKI possess luminal epithelium but fewer glandular structures compared to WT uteri (Figure 2(a)). Foxa2, which is implicated in uterine gland development, was significantly lower in the AF2ERKI uterus than WT which is consistent with less glandular morphology [33]. Though uterine tissue is the most sensitive organ of E2-responsiveness, the AF2ERKI uterus is iresponsive to not only endogenous E2 but also exogenous pharmacological levels of E2 (2 mg/kg) treatment to the ovariectomized animal [33]. This observation clearly suggests that the AF-2 of $\mathrm{ER} \alpha$ is indispensable for estra-

(a)

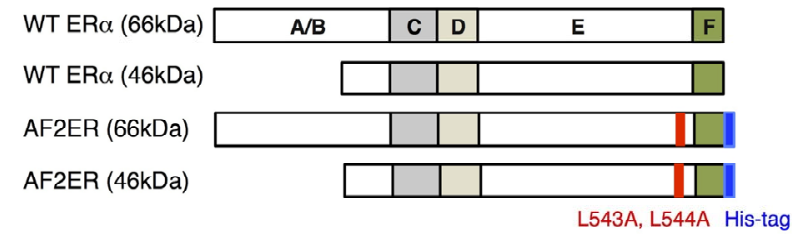

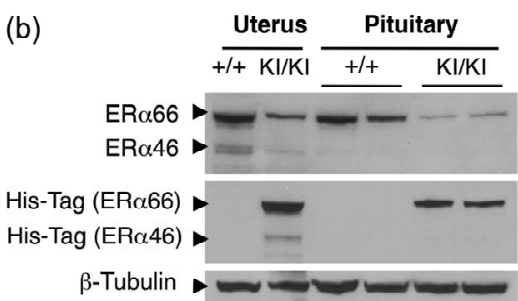

Figure 1. (a) Schematic diagram of WT and AF2ER-mutant $\mathrm{ER} \alpha$; (b) Representative results of Western blots probed for the ERa (ER $\alpha 66$ and ER $\alpha 46)$, His-tagged ER $\alpha$ (His-Tag) and $\beta$-Tubulin in the 8-week-old WT and AF2ERKI homozygote individual mouse uterus and pituitary are shown. $\boldsymbol{\beta}$-Tubulin was used as a loading control. +/+; WT, KI/KI; AF2ERKI homozygote. (Reproduced from [33]). 
(a)

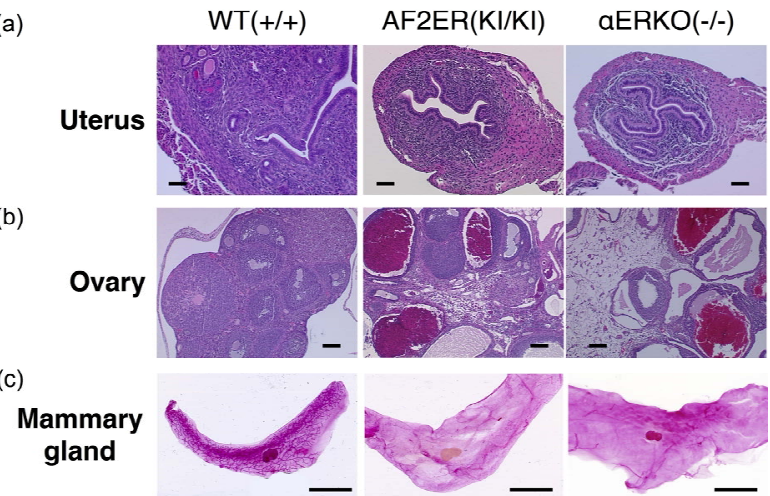

Figure 2. Histology of 8-week-old representative AF2ERKI female mice. (a) Uterine and (b) ovarian tissue H\&E staining from WT (left), AF2ERKI homozygote (middle) and $\alpha$ ERKO (left) mice. Scale bar $=100 \mu \mathrm{m}$; (c) Mammary gland whole mount Carmine Alum staining from 8-weekold representative mice. Scale bar $=1 \mathrm{~cm}$. (Reproduced from [33]).

diol responsiveness in uterine responses.

Growth factors, such as insulin like growth factor 1 (Igf1) and EGF are able to stimulate uterine cell proliferation without estrogen in ovariectomized WT mice but not in the $\alpha$ ERKO uteri [36]. This observation suggests that the growth factor dependent phosphorylation signals activate "ligand-independent" transcription through ER $\alpha$ in vivo [37]. However, Igf1 or EGF did not induce the uterine cell proliferation in AF2ERKI [33], suggesting that the AF-1 activity of ER $\alpha$ is regulated by the "liganddependent" functional domain AF-2.

The ovaries in the AF2ERKI female mice show cystic and hemorrhagic follicles, reminiscent of the $\alpha$ ERKO ovarian phenotype. A few primary follicles can be seen, but no corpora lutea were observed in AF2ERKI ovaries (Figure 2(b)). The hemorrhagic follicles develop after the prepubertal period. The gene expression profile of steroidogenic enzymes in the AF2ERKI ovary is also similar to the $\alpha \mathrm{ERKO}$ ovary [unpublished observation by YA, KJH and KSK].

In adult WT mice, the mammary ducts elongate to the end of the mammary fat pad and side branches from the primary ducts fill the fat pad. On the other hand, AF2ERKI mammary glands never develop beyond a rudimentary epithelial ductal tree similar to $\alpha$ ERKO females (Figure 2(c)). Taken together, these results suggest that estrogen-dependent AF-2 mediated transactivation of $\mathrm{ER} \alpha$ is essential for developing and maintaining female reproductive tissues.

\subsection{AF2ERKI Homozygote Male Reproduction}

AF2ERKI homozygote males sired no offspring during a continuous breeding study. The sperm count and motility were significantly lower in adult AF2ERKI male mice than WT. The morphological features of the AF2ERKI testis are characterized by dilated seminiferous tubules and rete testis (Figure 3). This phenotype is similar to what was seen previously in $\alpha$ ERKO male mice $[38,39]$. The dilation of the seminiferous tubule was observed in 20-day-old AF2ERKI males and in adults the tubule dilation was of similar severity as the $\alpha$ ERKO male mice. It has been reported that the repression of certain membrane proteins in the efferent duct of the $\alpha \mathrm{ERKO}$ is related to seminiferous tubule dilation and male infertility [40]. The expression level of the sodium/hydrogen exchanger 3 (Slc9a3), aquaporin 9 (Aqp9), carbonic anhydrase 2 (Car2) and Aqp1, all related to testicular fluid reabsorption in efferent ducts, were significantly decreased in the AF2ERKI efferent duct as seen in $\alpha$ ERKO males [34]. These results suggest that the AF-2 function is also indispensable for normal male reproduction. Serum hormone levels are disrupted in AF2ERKI male mice [34]. The AF2ERKI male has a 10 times higher level of testosterone than WT and that level was similar to the $\alpha$ ERKO male. However, the serum LH level in the AF2ERKI male was lower than the $\alpha$ ERKO and was similar to WT [34]. This might suggest differential usage of ER $\alpha$ AF-1 in negative feedback of the hypothalamicpituitary gonadal axis in male versus female mice.

\subsection{AF2ERKI Body Mass and Bone Density}

Estrogen is important in regulating body fat as evidenced by studies indicating ovariectomy leads to increased body weight in rodents [41] and further supported by the obesity of $\alpha$ ERKO [42] and Cyp19 (aromatase) KO females [43]. The body weights of 3-week-old male and female AF2ERKI mice were not different from WT. At 9 weeks, the body weights of AF2ERKI females were significantly higher than WT females and that level was comparable to the same age male mice, however the body weights of the AF2ERKI males were not different from WT (Figure 4). The body fat percentages of the AF2ERKI females were significantly higher than WT,

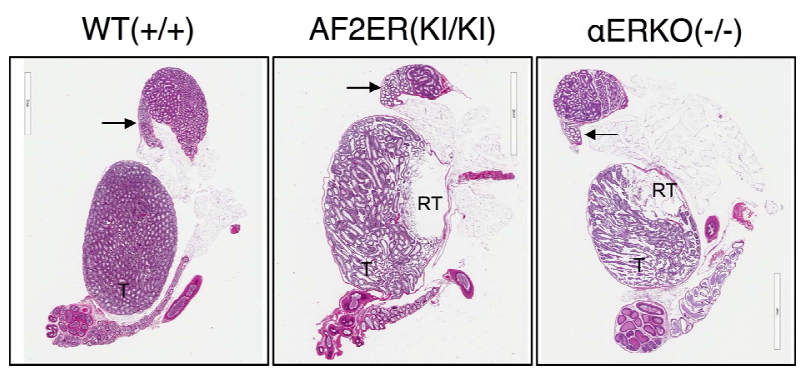

Figure 3. Representative longitudinal sections of adult WT, AF2ERKI homozygote and $\alpha$ ERKO testes and epididymis. Arrow indicates efferent duct, $T$ indicates testis, RT indicates rete testis. The bar in the figure indicates $3 \mathrm{~mm}$. (Reproduced from [34]). 

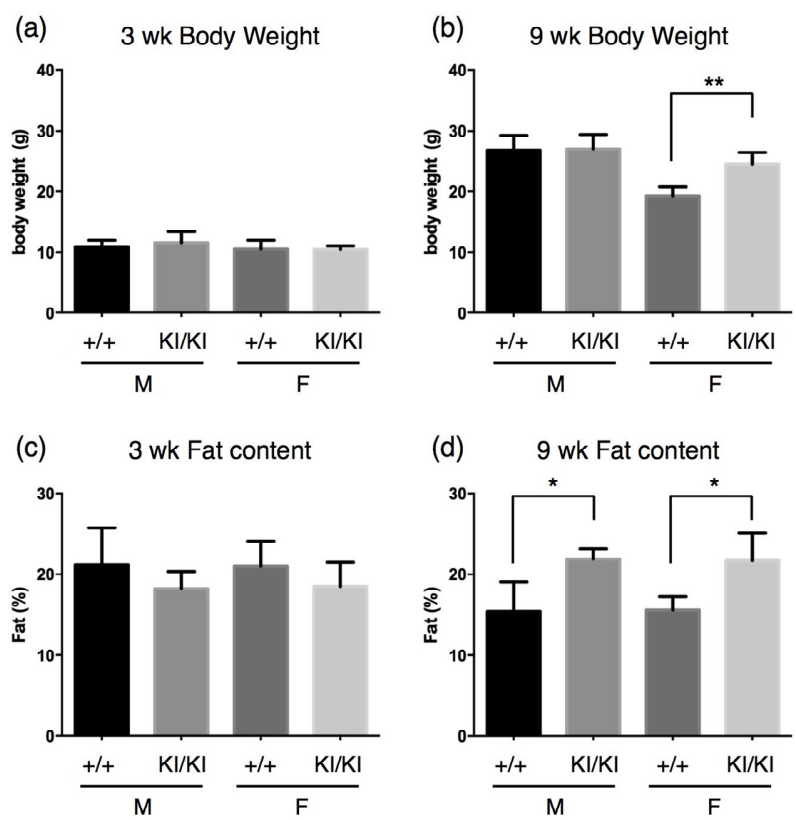

Figure 4. Body weight (a and $b$ ) and fat content (c and d) of 3-week and 9-week-old WT (+/+) and AF2ERKI homozygote $(\mathrm{KI} / \mathrm{KI})$ male $(\mathrm{M})$ and female $(\mathrm{F})$ mice. Fat content was analyzed by DEXA $(n=6)$. Data are expressed as mean \pm S.D. Statistical analysis was performed by unpaired t-test. indicates $\mathbf{p}<0.01,{ }^{*}$ indicates $\mathbf{p}<0.05$.

which may contribute to the increased body weights. Interestingly, the body fat percentages in 9-week-old AF2ERKI males were significantly higher than WT in spite of the fact that the body weights were not different between the genotypes (Figure 4).

Clinical as well as experimental data imply a role of estrogen in osteoprotective action. For example, bone mineral density (BMD) is lower in postmenopausal women, and in the castrated rodents. [44]. It has been reported that the BMD in the $\alpha \mathrm{ERKO}$ female is relatively normal. On the other hand, BMD in the male $\alpha \mathrm{ERKO}$ is significantly lower than WT [45]. There was no significant difference of BMD of the female femur between AF2ERKI and WT mice. In contrast, BMD of the male femur was significantly lower in 12-week-old AF2ERKI mice compared to WT mice and that level was similar to the female femur (Figure 5). The skeletal phenotypes of AF2ERKI mice are similar to those of the $\alpha$ ERKO mice.

\section{Antagonist Reversal Activity of AF2ER}

\subsection{ER $\alpha$ Antagonists Induce Estrogenic Responses in AF2ERKI Mouse Uterus}

As we described above, the AF2ER mutation diminished estradiol (E2) mediated physiological responses in mice. Interestingly, the AF2ER mutation reversed ER $\alpha$ antagonists, such as ICI or tamoxifen (TAM), into agonists. Ovariectomized female mice were injected in a 3-day bioassay with vehicle, ICI, TAM or E2. The treatment of E2 and TAM significantly induced the uterine weight of WT mice and ICI treatment was ineffective. In contrast, ICI and TAM treatment increased the AF2ERKI uterine weight but E2 treatment did not (Figure 6). The proliferation of endometrial epithelial cells in the AF2ERKI uterus was induced by ICI and TAM [33]. Estrogen responsive uterine genes in the WT female such as Igf1 and lactotransferrin were regulated similarly by ICI and TAM

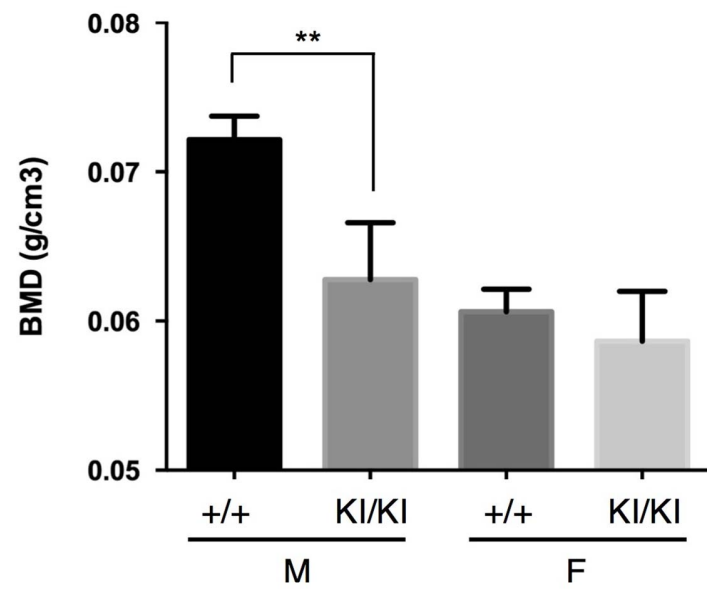

Figure 5. Bone mineral densities (BMD) of the femurs in 12-week-old WT (+/+) and AF2ERKI homozygote (KI/KI) male (M) and female (F) were analyzed by DEXA $(n=6)$. Data are expressed as mean \pm S.D.. Statistical analysis was performed by unpaired t-test. ${ }^{* *}$ indicates $p<0.01$.

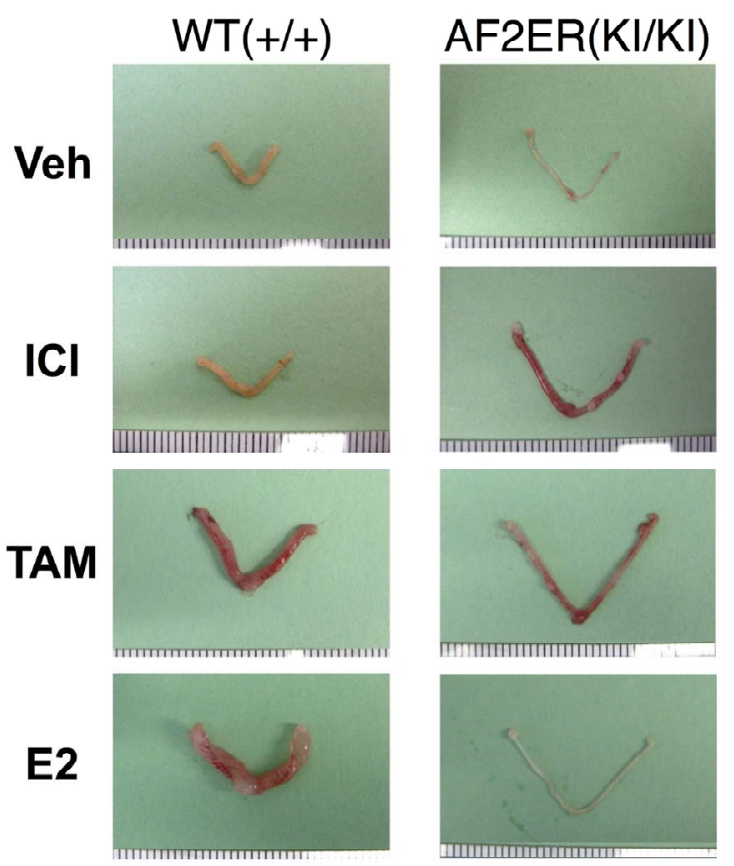

Figure 6. Representative view of whole uterus of ovariectomized mice after vehicle (Veh), ICI $(2 \mathrm{mg} / \mathrm{kg})$, TAM (2 $\mathrm{mg} / \mathrm{kg})$ or $\mathrm{E} 2(2 \mathrm{mg} / \mathrm{kg})$ treatments for three consecutive days. (Reproduced from [33]). 
in the AF2ERKI female [33]. We also demonstrated the AF2ER function in a receptive uterus model. Estrogen induces stromal cell proliferation but not epithelial cell proliferation in the receptive uterus. In the AF2ERKI uterus, ICI increased proliferation of stromal cells but not epithelial cells similar to E2 treated WT [33].

\subsection{ER $\alpha$ Antagonist Restored Male Fertility in AF2ERKI Male}

Antagonist reversal was also observed in AF2ERKI male mice [34]. 21-day-old AF2ERKI male mice were treated with TAM for 3 weeks, then used in a 2 month continuous breeding study. $75 \%$ of placebo-treated WT males were fertile during this period. Under the experimental conditions, $83 \%$ of TAM-treated WT males were fertile. In contrast, none of placebo-treated AF2ERKI males sired litters (0\%); however, 38\% of TAM-treated AF2ERKI males sired offspring, suggesting that TAM activated the AF2ER to restore fertility. TAM treatment induced efferent ductal gene expression (Slc9a3, Aqp1, Aqp9, and Car2) in AF2ERKI mice to the same level seen in WT mice, and at the same time the dysmorphology of AF2ERKI testis was resolved. TAM treatment restored the sperm motility but had no effect on the sperm count in AF2ERKI male mice [34].

\subsection{ER $\alpha$ Antagonists Did Not Regulate Estrogenic Responses in Pituitary}

Ovariectomy releases negative feedback in WT female mice, resulting in increased serum LH. Additionally, E2 replacement down regulates the serum $\mathrm{LH}$ in the WT female. In contrast, the increased serum LH level in ovariectomized AF2ERKI mice was not regulated by ICI or TAM treatment [33]. The level of $L h b$ mRNA in the ovariectomized AF2ERKI pituitary was not changed by ICI or TAM in parallel with the serum LH level [33]. Prolactin $(P r l)$ is a well-known estrogen responsive gene in the pituitary [46,47]. The basal level of $\mathrm{Prl}$ expression in the AF2ERKI pituitary was lower than WT and similar to the $\alpha$ ERKO pituitary. The expression of the Prl gene was not regulated by ICI or TAM in the AF2ERKI pituitary, whereas E2 activated the $\mathrm{Prl}$ gene expression in the WT pituitary [33]. These results indicate that the functionality of $\mathrm{ER} \alpha \mathrm{AF}-1$ or $\mathrm{AF}-2$ in the pituitary is different than their activities in the uterus.

\subsection{Molecular Mechanism of AF2ER-Mediated Antagonist Reversal}

We have explored the molecular mechanism of the antagonist reversal activity of AF2ER. The AF2ER mutation blocked the recruitment of p160 co-activators to the AF-2 with any ligand [48], thereby disrupting the E2 (agonist) dependent transcription activation. Even though
AF2ER does not recruit the transcription co-activators to AF-2, ICI and 4OHT (antagonists) activate AF2ER. We demonstrated that the truncation of the AF2ER N-terminal region diminished antagonist dependent transcription, thus the N-terminal localized transcription activity (AF-1) is essential for the antagonist reversal activity [33]. Several of our in vitro studies indicate that the mode of antagonist-mediated AF2ER activation is similar to the partial agonist activity of 4OHT on WT ER $\alpha$. Namely, the overexpression of transcription co-activator, p300/CBP enhanced both antagonist mediated AF2ER activation and 4OHT mediated WT ER $\alpha$ activation through the AF-1 domain of $\mathrm{ER} \alpha$ in a similar manner [33]. This observation supports the previous findings, which suggested that 4OHT mediated partial agonistic activity for WT ER $\alpha$ can only be mediated by AF-1 [10]. Further investigation revealed that the antagonists induce homodimerization of the AF2ER LBD, and the truncation of 41 amino acids of the C-terminal end (known as F-domain) diminished this homodimerization [49]. Interestingly, 4OHT also induced homodimerization of WT-LBD and F-domain truncation from the WT-LBD strongly reduced this dimerization similar to AF2ER. The prevention of dimer formation diminished the antagonist dependent AF2ER activation and this dimerization correlated with the ligand-dependent estrogen responsive DNA element binding activity [49].

One of the major antagonistic effects of ICI has been shown both in vivo and in vitro to result from loss of ER $\alpha$ protein through proteasome-mediated proteolysis [27,28]. As ICI is an agonist for AF2ER, we analyzed the effect of ICI on AF2ER protein stability in vitro. As expected, ICI induced the degradation of WT protein. On the contrary, ICI did not induce AF2ER protein degradation [49]. In the ICI-treated AF2ERKI female, the level of uterine AF2ER protein was not reduced, whereas the level of WT ER $\alpha$ was markedly reduced by ICI treatment [33]. These results suggest that the AF2ER mutation prevents the ICI-mediated proteolysis of $\mathrm{ER} \alpha$ protein and blocks loss of AF2ER protein in vivo and in vitro. Additionally, we confirmed that dimerization does not correlate with the ICI-dependent ER $\alpha$ protein degradation [49].

\section{Summary and Future Directions}

We describe here that the AF-2 of ER $\alpha$ is a critical domain to maintain the estrogen dependent physiological functions in female and male mice. Surprisingly, AF-2 core mutation disrupts the growth factor inducible cell proliferation in the AF2ERKI uterus, a phenomenon that has been recognized as a "ligand-independent" action of $\mathrm{ER} \alpha$. This result indicates that the proper positioning of helix 12 (AF-2) is neccesary for appropriate AF-1 functionality. Interestingly, the AF-2 mutation reversed antagonists to agonists. This antagonist dependent trans- 
criptional activity is derived from AF-1 similar to TAMmediated WT ER $\alpha$ activation. These results suggest that the AF2ER mutation disrupted helix 12 (AF-2) positioning with agonist or when unliganded, but do not affect the configulation of the LBD with SERMs (e.g. TAM). TAM regulates uterine gene expression in the AF2ERKI female, however not in the pituitary. This suggests the existence of differential tissue factors for AF-1 activation between the uterus and pituitary. The antagonist reversal activity in the AF2ERKI mouse model will be a useful to analyze the tissue selective agonist and antagonist activity of SERMs.

We find that the AF2ER mutation prevents ICI- dependent ER $\alpha$ proteolysis and that is an explanation for AF2ER activation. ICI is now categorized as a SERD which means SERDs may possess agonistic activity that is covered by their strong proteolysis inducible activity. SERD is a new concept of estrogen receptor modulation and it is still ambiguous with SERMs. The AF2ERKI model may be useful in classifying estrogen modulators into SERDs and SERMs.

Our preliminary results suggest that long-term TAM treatment to the AF2ERKI female prevents body weight gain compared to the vehicle treated group. This suggests that $\mathrm{ER} \alpha \mathrm{AF}-1$ related activity is involved in preventing female weight gain. It may be beneficial to screen estrogenic chemicals that prefer AF-1 activity to control obesity.

In conclusion, in vitro and in vivo experiments using the AF2ER mutant will help determine the AF-1 versus AF-2 dependent tissue selective action of estrogenic chemicals as it relates to their physiological activities of estrogen hormones and estrogen receptors.

\section{Acknowledgements}

We thank Dr. Y. Mishina, Dr. M. K. Rey and Mr. G. Scott for support to generate AF2ERKI mouse, Dr. E. M. Eddy, Dr. K. S. Janardhan and Ms. E. H. Goulding for analyses of AF2ERKI male mice, and Ms. S. C. Hewitt and Dr. W. Winuthayanon for critical reading of this manuscript. This research was granted to K. S. K. (Z01ES 70065) by the Intramural Research Program of the NIH, National Institute of Environmental Health Sciences.

\section{REFERENCES}

[1] D. J. Mangelsdorf, C. Thummel, M. Beato, P. Herrlich, G. Schütz, K. Umesono, B. Blumberg, P. Kastner, M. Mark, P. Chambon and R. M. Evans, "The Nuclear Receptor Superfamily: The Second Decade,” Cell, Vol. 83, No. 6, 1995, pp. 835-839. doi:10.1016/0092-8674(95)90199-X

[2] P. Germain, B. Staels, C. Dacquet, M. Spedding and V. Laudet, "Overview of Nomenclature of Nuclear Receptors,” Pharmacological Reviews, Vol. 58, No. 4, 2006, pp. 685-704. doi:10.1124/pr.58.4.2
[3] W. Wahli and E. Martinez, "Superfamily of Steroid Nuclear Receptors: Positive and Negative Regulators of Gene Expression,” FASEB Journal, Vol. 5, No. 9, 1991, pp. 2243-2249.

[4] W. Bourguet, P. Germain and H. Gronemeyer, "Nuclear Receptor Ligand-Binding Domains: Three-Dimensional Structures, Molecular Interactions and Pharmacological Implications," Trends in Pharmacological Sciences, Vol. 21, No. 10, 2000, pp. 381-388. doi:10.1016/S0165-6147(00)01548-0

[5] A. M. Brzozowski, A. C. Pike, Z. Dauter, R. E. Hubbard, T. Bonn, O. Engström, L. Ohman, G. L. Greene, J. A. Gustafsson and M. Carlquist, "Molecular Basis of Agonism and Antagonism in the Oestrogen Receptor," Nature, Vol. 389, No. 6652, 1997, pp. 753-758. doi:10.1038/39645

[6] J. M. Hall and D. P. McDonnell, "Coregulators in Nuclear Estrogen Receptor Action: From Concept to Therapeutic Targeting,” Molecular Interventions, Vol. 5, No. 6, 2005, pp. 343-357. doi:10.1124/mi.5.6.7

[7] K. A. Green and J. S. Carroll, “Oestrogen-Receptor-Mediated Transcription and the Influence of Co-Factors and Chromatin State,” Nature Reviews Cancer, Vol. 7, No. 9, 2007, pp. 713-722. doi:10.1038/nrc2211

[8] C. M. Klinge, "Estrogen Receptor Interaction with CoActivators and Co-Repressors,” Steroids, Vol. 65, No. 5, 2000, pp. 227-251. doi:10.1016/S0039-128X(99)00107-5

[9] J. A. Lees, S. E. Fawell and M. G. Parker, "Identification of Two Transactivation Domains in the Mouse Oestrogen Receptor,” Nucleic Acids Research, Vol. 17, No. 14, 1989, pp. 5477-5488. doi:10.1093/nar/17.14.5477

[10] M. Berry, D. Metzger and P. Chambon, "Role of the Two Activating Domains of the Oestrogen Receptor in the Cell-Type and Promoter-Context Dependent Agonistic Activity of the Anti-Oestrogen 4-Hydroxytamoxifen," EMBO Journal, Vol. 9, No. 9, 1990, pp. 2811-2818.

[11] R. S. Thomas, N. Sarwar, F. Phoenix, R. C. Coombes and S. Ali, "Phosphorylation at Serines 104 and 106 by Erk1/2 MAPK Is Important for Estrogen Receptor-Activity," Journal of Molecular Endocrinology, Vol. 40, No. 4, 2008, pp. 173-184. doi:10.1677/JME-07-0165

[12] S. Kato, H. Endoh, Y. Masuhiro, T. Kitamoto, S. Uchiyama, H. Sasaki, S. Masushige, Y. Gotoh, E. Nishida, H. Kawashima, D. Metzger and P. Chambon, "Activation of the Estrogen Receptor through Phosphorylation by Mitogen-Activated Protein Kinase," Science, Vol. 270, No. 5241, 1995, pp. 1491-1494. doi:10.1126/science.270.5241.1491

[13] G. Bunone, P. A. Briand, R. J. Miksicek and D. Picard, "Activation of the Unliganded Estrogen Receptor by EGF Involves the MAP Kinase Pathway and Direct Phosphorylation,” EMBO Journal, Vol. 15, No. 9, 1996, pp. 2174-2183.

[14] P. B. Joel, J. Smith, T. W. Sturgill, T. L. Fisher, J. Blenis and D. A. Lannigan, "pp90rsk1 Regulates Estrogen Receptor-Mediated Transcription through Phosphorylation of Ser-167," Molecular and Cellular Biology, Vol. 18, No. 4, 1998, pp. 1978-1984.

[15] H. Lahooti, R. White, S. A. Hoare, D. Rahman, D. J. Pap- 
pin and M. G. Parker, "Identification of Phosphorylation Sites in the Mouse Oestrogen Receptor," Journal of Steroid Biochemistry and Molecular Biology, Vol. 55, no. 3, 1995, pp. 305-313. doi:10.1016/0960-0760(95)00188-3

[16] S. Ali, D. Metzger, J. M. Bornert and P. Chambon, "Modulation of Transcriptional Activation by LigandDependent Phosphorylation of the Human Oestrogen Receptor A/B Region,” EMBO Journal, Vol. 12, No. 3, 1993, pp. 1153-1160.

[17] V. S. Likhite, F. Stossi, K. Kim, B. S. Katzenellenbogen and J. A. Katzenellenbogen, "Kinase-Specific Phosphorylation of the Estrogen Receptor Changes Receptor Interactions with Ligand, Deoxyribonucleic Acid, and Coregulators Associated with Alterations in Estrogen and Tamoxifen Activity," Molecular Endocrinology, Vol. 20, No. 12, 2006, pp. 3120-3132. doi:10.1210/me.2006-0068

[18] C. L. Waller, T. I. Oprea, K. Chae, H. K. Park, K. S. Korach, S. C. Laws, T. E. Wiese, W. R. Kelce and L. E. Gray, "Ligand-Based Identification of Environmental Estrogens," Chemical Research in Toxicology, Vol. 9, No. 8, 1996, pp. 1240-1248. doi:10.1021/tx960054f

[19] G. G. Kuiper, J. G. Lemmen, B. Carlsson, J. C. Corton, S. H. Safe, P. T. van der Saag, B. van der Burg and J. A. Gustafsson, "Interaction of Estrogenic Chemicals and Phytoestrogens with Estrogen Receptor Beta,” Endocrinology, Vol. 139, No. 10, 1998, pp. 4252-4263. doi:10.1210/en.139.10.4252

[20] R. M. Blair, “The Estrogen Receptor Relative Binding Affinities of 188 Natural and Xenochemicals: Structural Diversity of Ligands,” Toxicological Sciences, Vol. 54, No. 1, 2000, pp. 138-153. doi:10.1093/toxsci/54.1.138

[21] N. G. Coldham, M. Dave, S. Sivapathasundaram, D. P. McDonnell, C. Connor and M. J. Sauer, "Evaluation of a Recombinant Yeast Cell Estrogen Screening Assay,” Environmental Health Perspectives, Vol. 105, No. 7, 1997, pp. 734-742.

[22] Y. Arao, N. Kanamori, E. Kikkawa, H. Otsuka, Y. Arimoto, K. Ikeda, T. Inakuma and F. Kayama, “A Two-Step Screening Method, Using Estrogen Receptor-Mediated Transactivation, to Measure Estrogenicity in Edible Plants,” Food Chemistry, Vol. 104, No. 3, 2007, pp. 1288-1294. doi:10.1016/j.foodchem.2007.01.076

[23] V. C. Jordan and M. Morrow, "Tamoxifen, Raloxifene, and the Prevention of Breast Cancer," Endocrine Reviews, Vol. 20, No. 3, 1999, pp. 253-278. doi:10.1210/er.20.3.253

[24] D. McDonnell, "The Molecular Pharmacology of SERMs," Trends in Endocrinology \& Metabolism, Vol. 10, No. 8, 1999, pp. 301-311. doi:10.1016/S1043-2760(99)00177-0

[25] V. C. Jordan, "Tamoxifen: A Most Unlikely Pioneering Medicine,” Nature Reviews Drug Discovery, Vol. 2, No. 3, 2003, pp. 205-213. doi:10.1038/nrd1031

[26] C. L. Smith, "Coregulator Function: A Key to Understanding Tissue Specificity of Selective Receptor Modulators,” Endocrine Reviews, Vol. 25, No. 1, 2004, pp. 4571. doi:10.1210/er.2003-0023

[27] S. Dauvois, P. S. Danielian, R. White and M. G. Parker, "Antiestrogen ICI 164,384 Reduces Cellular Estrogen Receptor Content by Increasing Its Turnover,” Proceedings of the National Academy of Sciences of USA, Vol. 89, No. 9, 1992, pp. 4037-4041. doi:10.1073/pnas.89.9.4037

[28] M. K. Gibson, L. A. Nemmers, W. C. Beckman, V. L. Davis, S. W. Curtis and K. S. Korach, "The Mechanism of ICI 164,384 Antiestrogenicity Involves Rapid Loss of Estrogen Receptor in Uterine Tissue," Endocrinology, Vol. 129, No. 4, 1991, pp. 2000-2010. doi:10.1210/endo-129-4-2000

[29] A. Howell, "Pure Oestrogen Antagonists for the Treatment of Advanced Breast Cancer," Endocrine Related Cancer, Vol. 13, No. 3, 2006, pp. 689-706. doi:10.1677/erc.1.00846

[30] J. F. Couse and K. S. Korach, "Estrogen Receptor Null Mice: What Have We Learned and Where Will They Lead Us?” Endocrine Reviews, Vol. 20, No. 3, 1999, pp. 358-417. doi:10.1210/er.20.3.358

[31] D. B. Lubahn, J. S. Moyer, T. S. Golding, J. F. Couse, K. S. Korach and O. Smithies, "Alteration of Reproductive Function but Not Prenatal Sexual Development after Insertional Disruption of the Mouse Estrogen Receptor gene," Proceedings of the National Academy of Sciences of USA, Vol. 90, No. 23, 1993, pp. 11162-11166. doi:10.1073/pnas.90.23.11162

[32] S. C. Hewitt, G. E. Kissling, K. E. Fieselman, F. L. Jayes, K. E. Gerrish and K. S. Korach, "Biological and Biochemical Consequences of Global Deletion of Exon 3 from the Er $\alpha$ Gene,” The FASEB Journal, Vol. 24, No. 12, 2010, pp. 4660-4667. doi:10.1096/fj.10-163428

[33] Y. Arao, K. J. Hamilton, M. K. Ray, G. Scott, Y. Mishina and K. S. Korach, "Estrogen Receptor $\alpha$ AF-2 Mutation Results in Antagonist Reversal and Reveals Tissue Selective Function of Estrogen Receptor Modulators," Proceedings of the National Academy of Sciences of USA, Vol. 108, No. 36, 2011, pp. 14986-14991. doi:10.1073/pnas.1109180108

[34] Y. Arao, K. J. Hamilton, E. H. Goulding, K. S. Janardhan, E. M. Eddy and K. S. Korach, "Transactivating Function (AF) 2-Mediated AF-1 Activity of Estrogen Receptor $\alpha$ Is Crucial to Maintain Male Reproductive Tract Function," Proceedings of the National Academy of Sciences of USA, Vol. 109, No. 51, 2012, pp. 21140-21145. doi:10.1073/pnas.1216189110

[35] A. Mahfoudi, E. Roulet, S. Dauvois, M. G. Parker and W. Wahli, "Specific Mutations in the Estrogen Receptor Change the Properties of Antiestrogens to Full Agonists," Proceedings of the National Academy of Sciences of USA, Vol. 92, No. 10, 1995, pp. 4206-4210. doi:10.1073/pnas.92.10.4206

[36] S. W. Curtis, T. Washburn, C. Sewall, R. DiAugustine, J. Lindzey, J. F. Couse and K. S. Korach, "Physiological Coupling of Growth Factor and Steroid Receptor Signaling Pathways: Estrogen Receptor Knockout Mice Lack Estrogen-Like Response to Epidermal Growth Factor," Proceedings of the National Academy of Sciences of the United States of America, Vol. 93, No. 22, 1996, pp. 12626-12630. doi:10.1073/pnas.93.22.12626

[37] C. L. Smith, "Cross-Talk between Peptide Growth Factor and Estrogen Receptor Signaling Pathways,” Biology of Reproduction, Vol. 58, No. 3, 1998, pp. 627-632. 
doi:10.1095/biolreprod58.3.627

[38] E. M. Eddy, T. F. Washburn, D. O. Bunch, E. H. Goulding, B. C. Gladen, D. B. Lubahn and K. S. Korach, "Targeted Disruption of the Estrogen Receptor Gene in Male Mice Causes Alteration of Spermatogenesis and Infertility," Endocrinology, Vol. 137, No. 11, 1996, pp. 47964805. doi:10.1210/en.137.11.4796

[39] E. H. Goulding, S. C. Hewitt, N. Nakamura, K. Hamilton, K. S. Korach and E. M. Eddy, "Ex3 $\alpha$ ERKO Male Infertility Phenotype Recapitulates the $\alpha$ ERKO Male Phenotype,” Journal of Endocrinology, Vol. 207, No. 3, 2010, pp. 281-288. doi:10.1677/JOE-10-0290

[40] Q. Zhou, L. Clarke, R. Nie, K. Carnes, L. W. Lai, Y. H. Lien, A. Verkman, D. Lubahn, J. S. Fisher, B. S. Katzenellenbogen and R. A. Hess, "Estrogen Action and Male Fertility: Roles of the Sodium/Hydrogen Exchanger-3 and Fluid Reabsorption in Reproductive Tract Function," Proceedings of the National Academy of Sciences of the United States of America, Vol. 98, No. 24, 2001, pp. 1413214137. doi:10.1073/pnas.241245898

[41] L. Zhu, W. C. Brown, Q. Cai, A. Krust, P. Chambon, O. P. McGuinness and J. M. Stafford, "Estrogen Treatment after Ovariectomy Protects against Fatty Liver and May Improve Pathway-Selective Insulin Resistance,” Diabetes, Vol. 62, No. 2, 2013, pp. 424-434. doi:10.2337/db11-1718

[42] P. A. Heine, J. A. Taylor, G. A. Iwamoto, D. B. Lubahn and P. S. Cooke, "Increased Adipose Tissue in Male and Female Estrogen Receptor-Alpha Knockout Mice,” Proceedings of the National Academy of Sciences of the United States of America, Vol. 97, No. 23, 2000, pp. 1272912734. doi:10.1073/pnas.97.23.12729

[43] M. E. Jones, A. W. Thorburn, K. L. Britt, K. N. Hewitt, N. G. Wreford, J. Proietto, O. K. Oz, B. J. Leury, K. M. Ro- bertson, S. Yao and E. R. Simpson, "Aromatase-Deficient (ArKO) Mice Have a Phenotype of Increased Adiposity,” Proceedings of the National Academy of Sciences of the United States of America, Vol. 97, No. 23, 2000, pp. 12735-12740. doi:10.1073/pnas.97.23.12735

[44] J. E. Compston, “Sex Steroids and Bone,” Physiological Reviews, Vol. 81, No. 1, 2001, pp. 419-447.

[45] Y. Imai, S. Kondoh, A. Kouzmenko and S. Kato, "Minireview: Osteoprotective Action of Estrogens Is Mediated by Osteoclastic Estrogen Receptor-Alpha," Molecular Endocrinology, Vol. 24, No. 5, 2010, pp. 877-885. doi:10.1210/me.2009-0238

[46] R. A. Maurer and A. C. Notides, "Identification of an Estrogen-Responsive Element from the 5'-Flanking Region of the Rat Prolactin Gene," Molecular and Cellular Biology, Vol. 7, No. 12, 1987, pp. 4247-4254.

[47] K. M. Scully, A. S. Gleiberman, J. Lindzey, D. B. Lubahn, K. S. Korach and M. G. Rosenfeld, "Role of Estrogen Receptor-Alpha in the Anterior Pituitary Gland," Molecular Endocrinology, Vol. 11, No. 6, 1997, pp. 674-681. doi:10.1210/me.11.6.674

[48] J. E. Valentine, "Mutations in the Estrogen Receptor Ligand Binding Domain Discriminate between HormoneDependent Transactivation and Transrepression," Journal of Biological Chemistry, Vol. 275, No. 33, 2000, pp. 25322-25329. doi:10.1074/jbc.M002497200

[49] Y. Arao, K. J. Hamilton, L. A. Coons and K. S. Korach, "Estrogen Receptor $\alpha$ L543A, L544A Mutation Changes Antagonists to Agonists which Correlates with the Ligand Binding Domain Dimerization Associated with DNA Binding Activity," Journal of Biological Chemistry, Vol. 288, No. 29, 2013, pp. 21105-21116. doi:10.1074/jbc.M113.463455 